\title{
Trastuzumab mediates antibody-dependent cell-mediated cytotoxicity and phagocytosis to the same extent in both adjuvant and metastatic HER2/neu breast cancer patients
}

\author{
Branka Petricevic ${ }^{1 \dagger}$, Johannes Laengle ${ }^{1 \dagger}$, Josef Singer ${ }^{2,3}$, Monika Sachet $^{1}$, Judit Fazekas ${ }^{2,3}$, Guenther Steger ${ }^{4,5}$,
} Rupert Bartsch ${ }^{4,5}$, Erika Jensen-Jarolim ${ }^{2,3,5}$ and Michael Bergmann ${ }^{1,5^{*}}$

\begin{abstract}
Background: Monoclonal antibodies (mAb), such as trastuzumab are a valuable addition to breast cancer therapy. Data obtained from neoadjuvant settings revealed that antibody-dependent cell-mediated cytotoxicity (ADCC) is a major mechanism of action for the mAb trastuzumab. Conflicting results still call into question whether disease progression, prolonged treatment or concomitant chemotherapy influences ADCC and related immunological phenomena.

Methods: We analyzed the activity of ADCC and antibody-dependent cell-mediated phagocytosis (ADCP) of peripheral blood mononuclear cells (PBMCs) from human epidermal growth factor receptor 2 (HER2/neu) positive breast cancer patients receiving trastuzumab therapy either in an adjuvant $(n=13)$ or metastatic $(n=15)$ setting as well as from trastuzumab treatment-naive (t-naive) HER2/neu negative patients $(n=15)$. PBMCs from healthy volunteers $(n=24)$ were used as controls. ADCC and ADCP activity was correlated with the expression of antibody binding Fc-gamma receptor (FcyR)I (CD64), FcyRll (CD32) and FcyRIII (CD16) on CD14+ (monocytes) and CD56+ (NK) cells, as well as the expression of CD107a+ (LAMP-1) on CD56+ cells and the total amount of CD4+CD25+FOXP3+ $\left(T_{\text {reg }}\right)$ cells. In metastatic patients, markers were correlated with progression-free survival (PFS).

Results: ADCC activity was significantly down regulated in metastatic, adjuvant and t-naive patient cohorts as compared to healthy controls. Reduced ADCC activity was inversely correlated with the expression of CD107a on CD56+ cells in adjuvant patients. ADCC and ADCP activity of the patient cohorts were similar, regardless of treatment duration or additional chemotherapy. PFS in metastatic patients inversely correlated with the number of peripheral $T_{\text {reg }}$ cells.

Conclusion: The reduction of ADCC in patients as compared to healthy controls calls for adjuvant strategies, such as immune-enhancing agents, to improve the activity of trastuzumab. However, efficacy of trastuzumab-specific ADCC and ADCP appears not to be affected by treatment duration, disease progression or concomitant chemotherapy. This finding supports the application of trastuzumab at any stage of the disease.
\end{abstract}

Keywords: ADCC, ADCP, HER2/neu, Breast cancer, Trastuzumab

\footnotetext{
*Correspondence: michael.bergmann@meduniwien.ac.at

${ }^{\dagger}$ Equal contributors

'Department of Surgery, Medical University of Vienna, Vienna General Hospital, Waehringer Guertel 18-20, Vienna A-1090, Austria

${ }^{5}$ Comprehensive Cancer Center Vienna, Spitalgasse 23, Vienna A-1090, Austria

Full list of author information is available at the end of the article
} 


\section{Background}

Immunotherapy based on monoclonal antibodies (mAb) targeting tumor-associated antigens (TAA) such as trastuzumab (anti-human epidermal growth factor receptor 2; HER2/neu) is clinically effective [1-6] and has thus become the standard of care for women with HER2/neu expressing breast cancer [7-9]. However, when administered as a monotherapy, this drug only yields response rates of $12 \%$ to $35 \%$ [10-12]. Understanding the key mechanisms, which underlie the therapeutic efficacy of trastuzumab would enable oncologists to exclude patients from therapy who probably do not benefit, and might also help to assist in the development of adjuvant therapies that enhance the therapeutic effects of this antibody.

It has been postulated that trastuzumabs' anti-tumor activity depends on multiple direct or indirect cytostatic and/or cytotoxic effects [13-17]. Direct binding can induce HER2/neu down regulation and the alteration of several HER2/neu dependent cellular signaling pathways leading to tumor growth inhibition. However, loss of HER2/neu expression [18,19] and cell signal transduction inhibition was not necessarily relevant for the development of resistance to trastuzumab in vivo and in a nude mouse model [20,21].

Studies on animal models revealed that the therapeutic activity of trastuzumab critically depends on the involvement of Fc-gamma receptor (FcyR)-expressing lymphocytes [22,23]. With respect to FcyRI (CD64) and FcyRIII (CD16) it could be demonstrated that mice lacking those two receptors were unable to mount protective immune responses against a virus-encoded tumor-specific antigen [24]. These studies indicate that antibody-dependent cellmediated cytotoxicity (ADCC) is a major mechanism of action for mAb. Moreover, trastuzumab present in breast cancer patients' serum after neoadjuvant application significantly enhanced their ADCC activity [25,26]. It is important to note that ADCC correlated with therapeutic response in that limited number of patients. In a metastatic setting the correlation of ADCC and therapeutic success is less clear. Some authors found that higher ADCC was predictive of the lack of disease progression [27], while other pilot studies did not observe a significant association $[28,29]$. Due to contradictory results, ADCC is currently regarded to be insufficient for the treatment of metastatic cancer [30]. This would imply that different mechanisms of trastuzumab, which are able to induce cell death, are relevant at the later stages of the disease. Thus, we concluded that more clinical data is required to gain better understanding if disease progression and prolonged treatment affects ADCC and its related immune parameters, which could then allow a functional design for immune enhancing strategies and their proper applications.

Therefore, we investigated the impact of disease status, adjuvant or metastatic, on ADCC and antibody-dependent cell-mediated phagocytosis (ADCP) in HER2/neu breast cancer patients receiving trastuzumab. We also included trastuzumab treatment-naive (t-naive) patients, which were HER2/neu negative. Recently, a three-color flow cytometric method has been developed to evaluate simultaneously ADCC and ADCP [31]. This technique has been further adapted for trastuzumab and HER2/neu overexpressing cancer cells [32]. Using this method, we analyzed the reactivity of peripheral blood mononuclear cells (PBMCs) of adjuvant, metastatic and t-naive patients. Further, we correlated this reactivity with the expression of Fc-gamma receptors and the amount of regulatory $\mathrm{T}$ $\left(\mathrm{T}_{\text {reg }}\right)$ cells as a surrogate parameter for tumor-associated immunosuppression.

\section{Materials and methods \\ Study collective}

15 metastatic and 13 adjuvant HER2/neu breast cancer patients were enrolled in the study. All received trastuzumab, starting with a loading dose of $8 \mathrm{mg} / \mathrm{kg}$, followed by $6 \mathrm{mg} / \mathrm{kg}$ in a standard 3 week cycle. 15 HER $2 /$ neu negative breast cancer patients served as a trastuzumab treatment-naive ( $\mathrm{t}$-naive) group (patient characteristics are shown in Table 1). Adjuvant patients received trastuzumab treatment for 1 year, whereas metastatic patients were treated with trastuzumab until intolerable toxicities, disease progression and switch to lapatinib or death occurred. Blood samples were taken prior to a new trastuzumab application. Patients did neither receive radiotherapy nor underwent any surgical intervention for at least 4 weeks prior to blood sampling. 24 healthy volunteers served as a control group for the patient collective. Clinical responses were determined according to response evaluation criteria in solid tumors (RECIST). Progressionfree survival (PFS) was assessed in a 1-year follow-up.

\section{Cell line}

The human breast adenocarcinoma cell line SKBR3 (ATCC, Manasses, VA, USA) was grown in RPMI 1640 medium with $2 \mathrm{mM}$ stable l-glutamine (PAA Laboratories, Pasching, Austria) and an addition of 10\% heat inactivated fetal calf serum (FCS; Linaris, WertheimBettingen, Germany). SKBR3 cells served as target ( $T$ ) cells in the ADCC/ADCP assay.

\section{Isolation of PBMCs}

Peripheral blood was drawn into ethylene diamine tetraacetic acid (EDTA) tubes (Greiner Bio-One, Kremsmünster, Austria) and processed at room temperature (RT). PBMCs were isolated by Ficoll-Paque (Amersham Pharmacia Biotech, Uppsala, Sweden) gradient centrifugation. One aliquot of the PBMCs was resuspended in RPMI 1640 medium with $2 \mathrm{mM}$ stable glutamine (PAA Laboratories) containing 25\% FCS (Linaris) and 5\% dimethyl sulfoxide 
Table 1 Clinical characteristics of participants

\begin{tabular}{|c|c|c|c|c|}
\hline & Healthy & Adjuvant & Metastatic & T-Naive \\
\hline Number, N & 28 & 13 & 15 & 15 \\
\hline \multicolumn{5}{|l|}{ Age, years } \\
\hline Median & 30 & 58 & 68 & 64 \\
\hline Range & $23-55$ & $37-82$ & $40-75$ & $34-74$ \\
\hline \multicolumn{5}{|c|}{ HER2/neu receptor, N (\%) } \\
\hline Positive & N.A. & $13(100 \%)$ & $15(100 \%)$ & $0(0 \%)$ \\
\hline Negative & & $0(0 \%)$ & $0(0 \%)$ & $15(100 \%$ \\
\hline \multicolumn{5}{|l|}{ Estrogen receptor, N (\%) } \\
\hline Positive & N.A. & $9(69 \%)$ & $8(44 \%)$ & $11(70 \%)$ \\
\hline Negative & & $4(31 \%)$ & $7(46 \%)$ & $4(30 \%)$ \\
\hline \multicolumn{5}{|c|}{ Progesterone receptor, N (\%) } \\
\hline Positive & N.A. & $5(38 \%)$ & $1(10 \%)$ & $7(40 \%)$ \\
\hline Negative & & $8(62 \%)$ & $14(90 \%)$ & $8(60 \%)$ \\
\hline Trastuzumab, N & N.A. & $13(100 \%)$ & $15(100 \%)$ & N.A. \\
\hline $\begin{array}{l}\text { Median application } \\
\text { time, months }\end{array}$ & & 7 & 58 & \\
\hline IQR & & 5 & 45 & \\
\hline \multicolumn{5}{|l|}{ Chemotherapy, N (\%) } \\
\hline FEC & N.A. & $1(10 \%)$ & & $1(10 \%)$ \\
\hline FEC-Doc & & & & $1(10 \%)$ \\
\hline EC & & & & $3(20 \%)$ \\
\hline EC-D & & & & $2(10 \%)$ \\
\hline CMF & & $1(10 \%)$ & & \\
\hline Docetaxel + Epirubicin & & $3(20 \%)$ & $1(10 \%)$ & \\
\hline Docetaxel & & $1(10 \%)$ & & \\
\hline Vinorelbin & & $1(10 \%)$ & $1(10 \%)$ & \\
\hline Carboplatin & & & $1(10 \%)$ & \\
\hline Paclitaxel & & & & $1(10 \%)$ \\
\hline
\end{tabular}

$\mathrm{N}$ : number of individuals; N.A.: not applicable; IQR: Interquartile range; FEC: 5-Fluorouracil, Epirubicin and Cyclophosphamide; FEC-Doc: 5-Fluorouracil, Epirubicin, Cyclophosphamide and Docetaxel; EC: Epirubicin and Cyclophosphamide; EC-D: Epirubicin, Cyclophosphamide and Docetaxel; CMF Cyclophosphamide, Methotrexate and 5-Fluorouracil.

(DMSO; Sigma Aldrich, Steinheim, Germany) followed by an intermediate cooling over night at $-80^{\circ} \mathrm{C}$, and stored afterwards in liquid nitrogen for later marker analysis. he rest of the freshly isolated PBMCs was used as effector (E) cells in the ADCC/ADCP assay.

\section{$A D C C$ and $A D C P$ assay}

ADCC/ADCP activity of PBMCs was measured in a three-color flow cytometric assay [31,32]. This recently established method is capable of providing data for ADCC and ADCP performance simultaneously. SKBR3 cells $\left(1 \times 10^{6}\right)$ were incubated with $1 \mu$ l of $0.5 \mathrm{mM}$ carboxyfluorescein diacetate succinimidyl ester (CFSE; Invitrogen, Eugene, OR, USA) in $\mathrm{PBS}$ for $10 \mathrm{~min}$ at $37^{\circ} \mathrm{C}$.
Cells were washed in ice cold SKBR3 medium and returned to normal cell culture conditions 24 hours prior to the assay. The following day effector cells were mixed with target cells at an E/T ratio of $25: 1\left(12.5 \times 10^{6} / \mathrm{ml}\right.$ effector cells, $5 \times 10^{5} / \mathrm{ml}$ target cells; final volume: $400 \mu \mathrm{l}$ ) and incubated with or without antibodies (trastuzumab, rituximab; Roche, Basel, Switzerland) at a concentration of $2.5 \mu \mathrm{g} / \mathrm{ml}$ for 2.5 hours at $37^{\circ} \mathrm{C}$ in a humidified atmosphere of $5 \% \mathrm{CO}_{2}$. Subsequently, effector cells were labeled with CD45 PE (Immunotech, Beckman Coulter, Marseille, France), and dead cells with 7-aminoactinomycin D (7-AAD; eBioscience, San Diego, CA, USA) followed by a three-color flow cytometric analysis, carried out on a Gallios ${ }^{\text {tix }}$ device (Beckman Coulter). CFSE \& 7AAD double positive cells represented tumor target cells killed by ADCC, whereas CFSE \& CD45 double positive cells were defined as tumor cells phagocytized by immune cells (ADCP). The amount of ADCC/ADCP activity was compared between cancer patients and healthy volunteers. Moreover, ADCC/ADCP levels of patients were correlated with different PBMC markers and PFS.

\section{Flow cytometric analysis of PBMCs}

For the evaluation of $\mathrm{T}_{\text {reg }}$ cells, IntraPrep (Immunotech) was used for fixation and permeabilization followed by staining with anti-forkhead-box-protein 3 (FOXP3) PE (eBioscience), anti-CD4 ECD (Immunotech) and antiCD25 FITC (BD Pharmingen, Franklin Lakes, NJ, USA) antibodies. Natural killer (NK) cells were defined by antiCD56 FITC (Sigma Aldrich). Monocytes were labeled with anti-CD14 FITC (BD Pharmingen). Expression of FcyRI was achieved by staining with anti-CD64 PC5 (Immunotech), FcyRII with anti-CD32 PE (Acris Antibodies GmbH, Herford, Germany) and FcyRIII with anti-CD16 PE (Immunotech). The lysosomal-associated membrane protein 1 (LAMP-1) expression was determined by antiCD107a FITC (BD Pharmingen). IgG1 (Mouse) FITC/PE, IgG1 (Mouse) PC5 and IgG1 (Mouse) ECD (Immunotech) antibodies served as isotype controls.

\section{Statistical analysis}

Statistical analyses were based on non-parametric tests and carried out with IBM SPSS Statistics 20.0.0 software (SPSS Inc., Chicago, IL, USA). Differences between the 3 groups were established using the Mann-Whitney-UTest. Correlations between the measured parameters were assessed using Spearman's rank correlation coefficient. A receiver operating characteristic curve (ROC) was conducted to estimate a cut-off value for PFS. KaplanMeier curves were calculated to show PFS within the period of the follow-up, and were compared with a LogRank test. For all statistical tests a two-sided p-value of $\leq 0.05$ was considered significant. 
Data presented by box- and whiskers-plots: The first and third quartiles are shown as boxes, including the median. The whiskers display 1.5 times the interquartile range (IQR). Dots represent outliers between 1.5 and 3 times the IQR. Triangles symbolize extreme outliers above 3 times the IQR.

\section{Ethics statement}

This study protocol was approved by the "Ethics Committee of the Medical University of Vienna" (\#445/2010). All patients and healthy volunteers gave consent after obtaining written information.

\section{Results}

First, we determined the potential of HER2/neu antibodyspecific ADCC and ADCP in breast cancer patients. HER2/neu-specific ADCC was significantly reduced in the adjuvant $(\mathrm{p}=0.02)$, metastatic $(\mathrm{p}=0.002)$ and $\mathrm{t}$-naive group ( $\mathrm{p}<0.001$ ), when compared to healthy controls (Figure 1). Similar results were obtained with an E/T ratio of 12.5:1 (Additional file 1: Figure S1). For trastuzumab treatment-naive patients we observed lower baseline ADCC activity compared to all other groups ( $\mathrm{p}<0.001)$.

Analyzing ADCP, we observed significant reduction in the adjuvant group $(p=0.003)$ and $t$-naive group $(\mathrm{p}=0.004)$ compared to healthy controls. In metastatic patients, a tendency towards reduced ADCP was observed (Figure 2). Here it is notable that adjuvant patients were treated with anti-HER2/neu antibodies for a median time of 7 months $(I Q R=5)$, while metastatic patients were treated for 58 months (IQR $=45)$. However, neither treatment duration nor chemotherapy

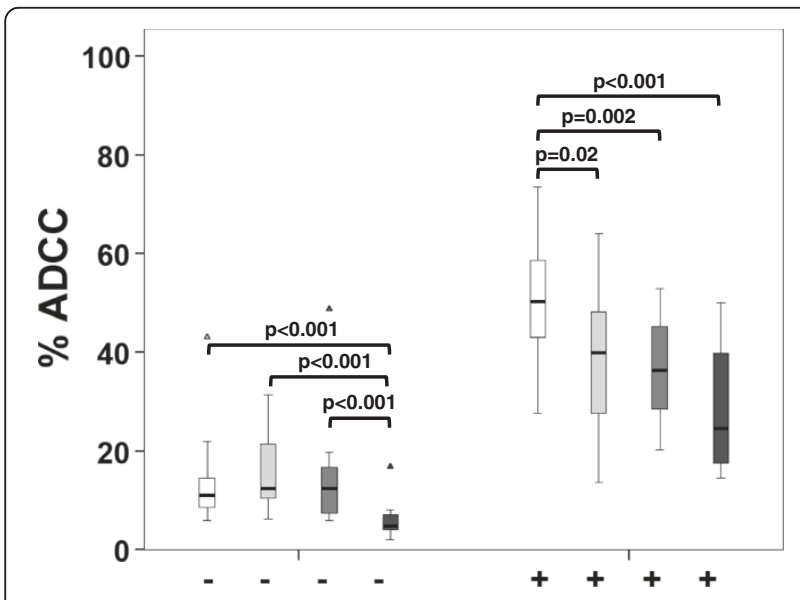

Figure 1 Trastuzumab-mediated ADCC of healthy volunteers and breast cancer patients. The extent of ADCC was determined by flow cytometry and is shown in \% of total tumor cell counts. An $E / T$ ratio of 25:1 was used. White boxplots represent healthy volunteers, light grey adjuvant, grey metastatic and dark grey trastuzumab naive (t-naive) breast cancer patients. The addition of trastuzumab is indicated at the bottom (-/+).

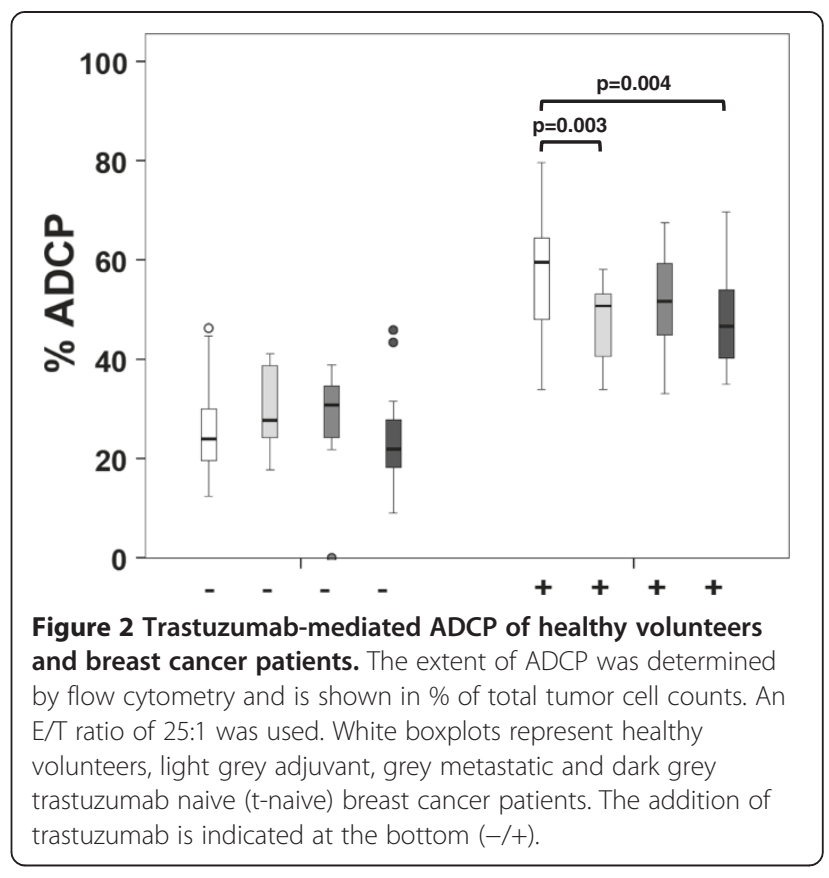

within the preceding 3 months had an effect on ADCC (Figure 3A, C) or ADCP efficiency (Figure 3B, D). Similar results were obtained using an E/T ratio of 12.5:1 (Additional file 2: Figure S2).

As the main effector cells of antibody-mediated tumor cell killing of PBMCs are monocytes (CD14+) and NK cells (CD56+), we investigated the singular contributions of these two immune cell populations on ADCC and ADCP activity. NK cells triggered in the presence of trastuzumab substantial and significant levels of ADCC $(\mathrm{p}=0.002)$ but not of ADCP, whereas the picture was completely opposite for monocytes (Additional file 3: Figure S3A, B). Monocytes achieved high levels of phagocytosis $(\mathrm{p}=0.001)$ but no significant cytotoxicity.

Concerning complement-dependent cytotoxicity (CDC), a trend towards trastuzumab-mediated CDC of cancer cells was observed (Additional file 4: Figure S4, Additional file 5: Supplementary methods), but this effect was not significant. This is in line with previous studies stating that CDC is indeed induced, but is not a major mechanism of action for trastuzumab, except in combination with CDC-enhancing agents [33].

ADCC and ADCP are mediated by subpopulations of CD56+ and CD14+ cells, respectively. Therefore, we determined the expression of Fc $\gamma$ RI (CD64), Fc $\gamma$ RII (CD32) and FcyRIII (CD16) on the above-mentioned subpopulations in our patients. Expression of CD16 was significantly increased in CD14+ cells of patients treated in a metastatic or adjuvant setting as well as in the t-naive group ( $\mathrm{p}=0.001, \mathrm{p}=0.003$ and $\mathrm{p}=0.003$ respectively), as compared to healthy controls (Figure 4A). In contrast, CD56+ cells showed a decrease of CD16 in the adjuvant 

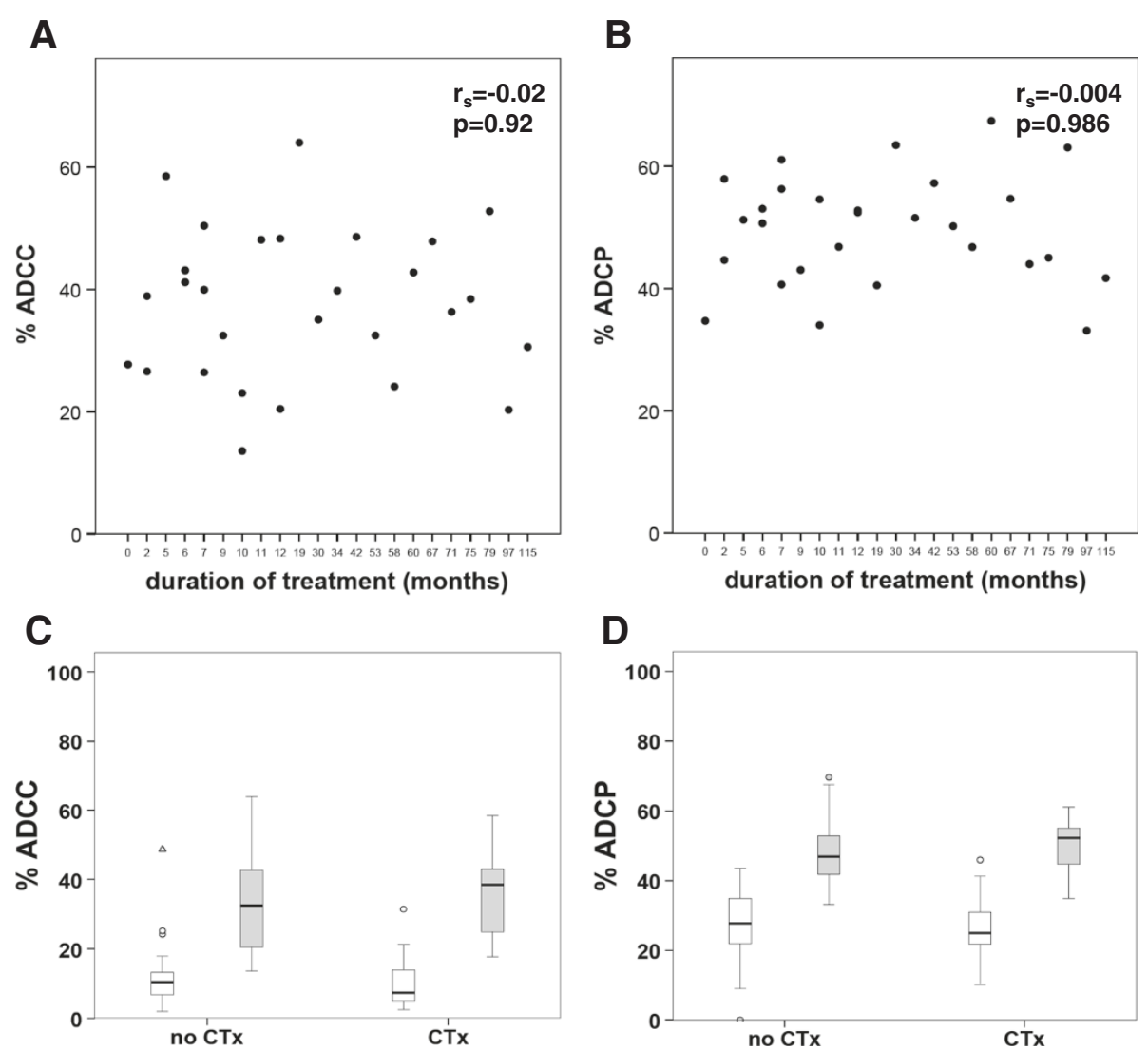

Figure 3 Influence of treatment duration and chemotherapy applied in the last 3 months on trastuzumab-mediated ADCC/ADCP. The extent of ADCC/ADCP was determined by flow cytometry and is shown in \% of total tumor cell counts. An E/T ratio of 25:1 was used. White boxplots represent baseline ADCC/ADCP without trastuzumab (-) and light grey stimulation with trastuzumab (+). Applied chemotherapy (CTX) is indicated on the bottom. A, C) ADCC. B, D) ADCP.

$(\mathrm{p}=0.006)$, metastatic $(\mathrm{p}=0.013)$ and $\mathrm{t}$-naive $(\mathrm{p}=0.001)$ group (Figure 5A). The expression of CD32 on monocytes showed differences between the study cohorts (Figure 4C). However, on NK cells this receptor was hardly detectable (Figure 5D). CD64 expression was consistent on CD14+ cells in all cohorts (Figure 4B), but almost undetectable on CD56+ cell (Figure 5B). LAMP-1 (CD107a), a degranulation marker indicating cytotoxic activation $[34,35]$, was up regulated in the adjuvant cohort $(\mathrm{p}=0.034)$, as compared to healthy controls (Figure 5C). The percentage of $\mathrm{T}_{\text {reg }}$ cells of all CD4+ cells was not significantly altered in any of the groups (Figure 6).

Moreover, we evaluated whether there was a correlation between HER2/neu-specific ADCC/ADCP activity and any $\mathrm{CD} 14+$ or CD56+ subpopulation measured above. Patients in the adjuvant setting showed negative correlations between CD56+CD107a+ cells (Figure 7; $\left.r_{s}=-0.797\right)$ and ADCC. Similar results were obtained at an E/T ratio of 12.5:1 (Additional file 6: Figure S6; $\left.\mathrm{r}_{\mathrm{s}}=-0.8\right)$. In healthy controls, metastatic and $\mathrm{t}$-naive patients there was no correlation between any investigated marker on PBMCs and ADCC/ADCP activity.
We analyzed the predictive value of the parameters mentioned above for PFS in metastatic patients assessed in a 1-year follow-up. For this purpose, ROC analysis was applied to measure the prognostic power by the area under the curve, and to determine a threshold for prediction of PFS. This revealed that only the number of $\mathrm{T}_{\text {reg }}$ cells could significantly predict PFS (Figure 8A; AUC $=0.970, p=0.004)$. Moreover, taking the cut-off value at $1.1 \%$ of $\mathrm{T}_{\text {reg }}$ cells of the amount of CD4+ cells resulted in a diagnostic sensitivity and specificity of $90 \%$ and $80 \%$, respectively. There was a significant difference $(p=0.022)$ between the groups above and below this value and permitted a hypothetical prediction of PFS depicted by Kaplan-Meier curves (Figure 8B).

\section{Discussion}

In this study, we demonstrated that neither disease progression nor duration of antibody treatment or chemotherapy had an impact on ADCC in HER2/neu breast cancer patients. This finding, that trastuzumab-mediated ADCC levels were not influenced by the treatment duration, is in line with the recent PHARE trial, which 


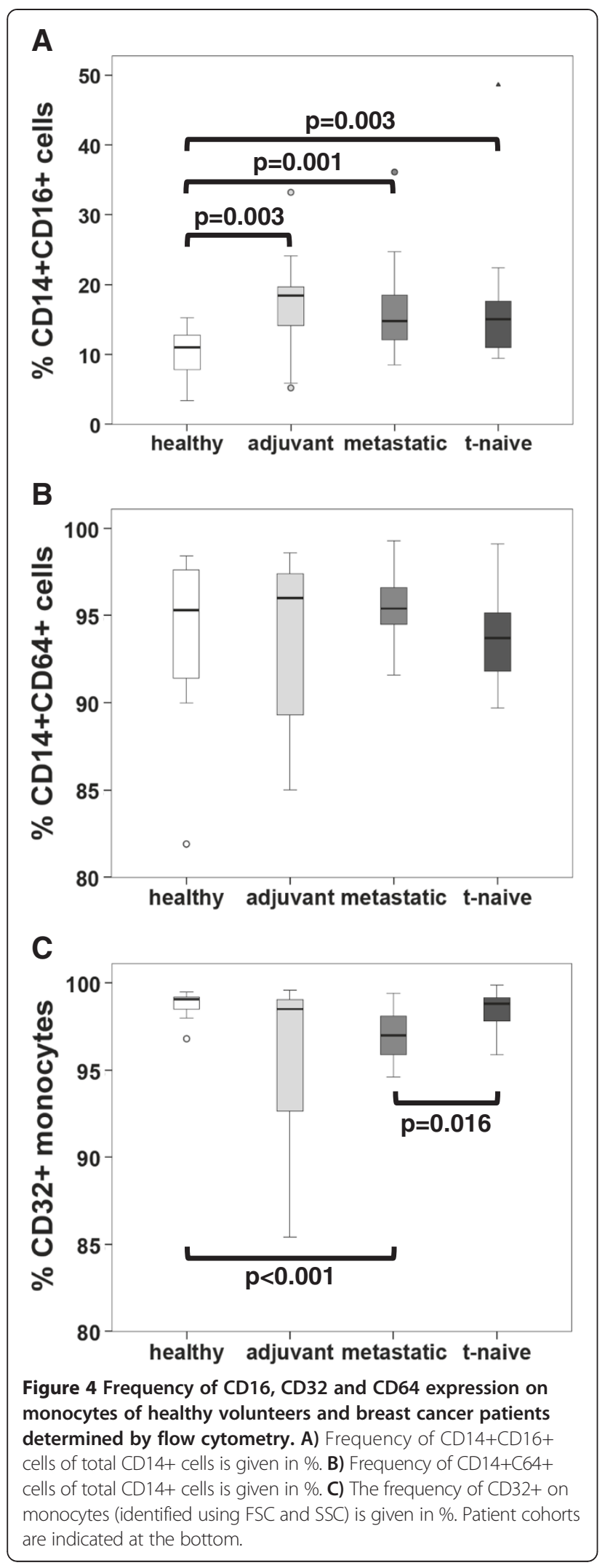

affirmed the recommendation for a 12-month standard treatment compared to 6 months of adjuvant treatment [36]. Nonetheless ADCC was lower in breast cancer patients as compared to healthy controls. This is also the first study indicating ADCP occurrence in this type of patients during treatment. In contrast to the popular belief that the immune mechanisms of antibody treatment deteriorate in metastatic cancer [30], our data indicates that trastuzumab stimulates ADCC in the metastatic setting as effectively as in the adjuvant setting. This supports the current clinical concept that trastuzumab treatment can be applied beyond disease progression [37-39] and at the same time underlines the relevance of ADCC as the major mechanism at any stage of the disease.

Chemotherapy associated immunosuppression leading to reduced levels of activated CD56+ cells in breast cancer [40] appears to play a minor role for trastuzumabdependent ADCC. This could be attributed to the fact that chemotherapy regimens of breast cancer patients frequently contain taxanes, which are known to stimulate the immune system [41].

Analyzing cell types that are relevant for antibody therapy, we found that CD16 expression on CD56+ cells was reduced in all patient cohorts. Previously, it had been shown in an in vitro stimulated cell culture trial that ADCC activity leads to a reduction of this cell type [26]. Thus, we hypothesize that one reason for the reduction of these particular cells in patient samples may be that ADCC had already occurred in patients. We favor this hypothesis over the notion that CD56+CD16+ cells are reduced in tumors due to immunosuppression, as we did not see a difference between adjuvant and metastatic patients, the latter being likely more affected by immunosuppression. Since we observed lower ADCC activity in all patients as compared to healthy control subjects, we suggest that treatment might potentially lead to an inhibition of ADCC, in part due to a decrease in ADCP reactivity. Thus, adjuvant immunotherapies need to be developed to counteract this effect. Moreover, we did not see a correlation between CD56+CD16+ cells and ADCC as observed by others [26]. An explanation for this could be the fact, that Varchetta et al. assessed ADCC prior to therapy or early during therapy, whereas we determined immune parameters after prolonged therapy.

We also found an up regulation of CD107a on CD56+ cells in the adjuvant patient cohort. CD107a up regulation has also been shown to occur in vitro following ADCC, as this protein is a parameter for degranulation $[34,35]$. Thus, we again hypothesize that the modulation of this receptor is an indication that ADCC had occurred in vivo in those patients rather than representing a therapy-independent up regulation. Thus, increased CD107a expression could be interpreted as a sign for 

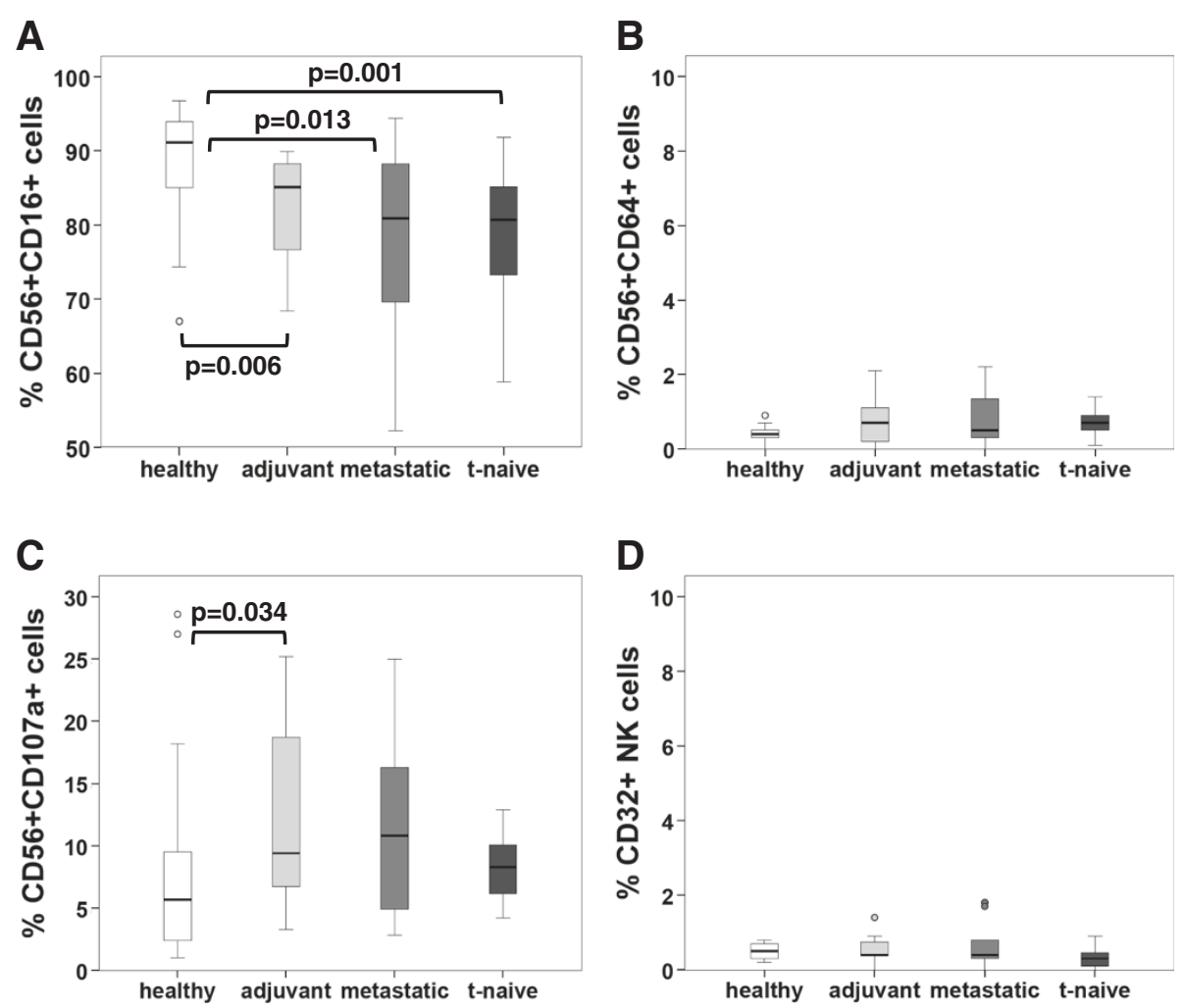

Figure 5 Frequency of $\mathrm{CD} 16, \mathrm{CD} 32, \mathrm{CD} 64$ and CD107a expression on NK cells of healthy volunteers and breast cancer patients determined by flow cytometry. A) The frequency of CD56+CD16+ cells of total CD56+ cells is given in \%. B) Frequency of CD56+CD64+ cells of total of CD56+ cells is given in \%. C) Frequency of CD56+C107a+ cells of total CD56+ cells is given in \%. D) The frequency of CD56+CD32+ of total CD56+ cells using lymphocyte gate (defined by FSC and SSC) is given in \%. Patient cohorts are indicated at the bottom.
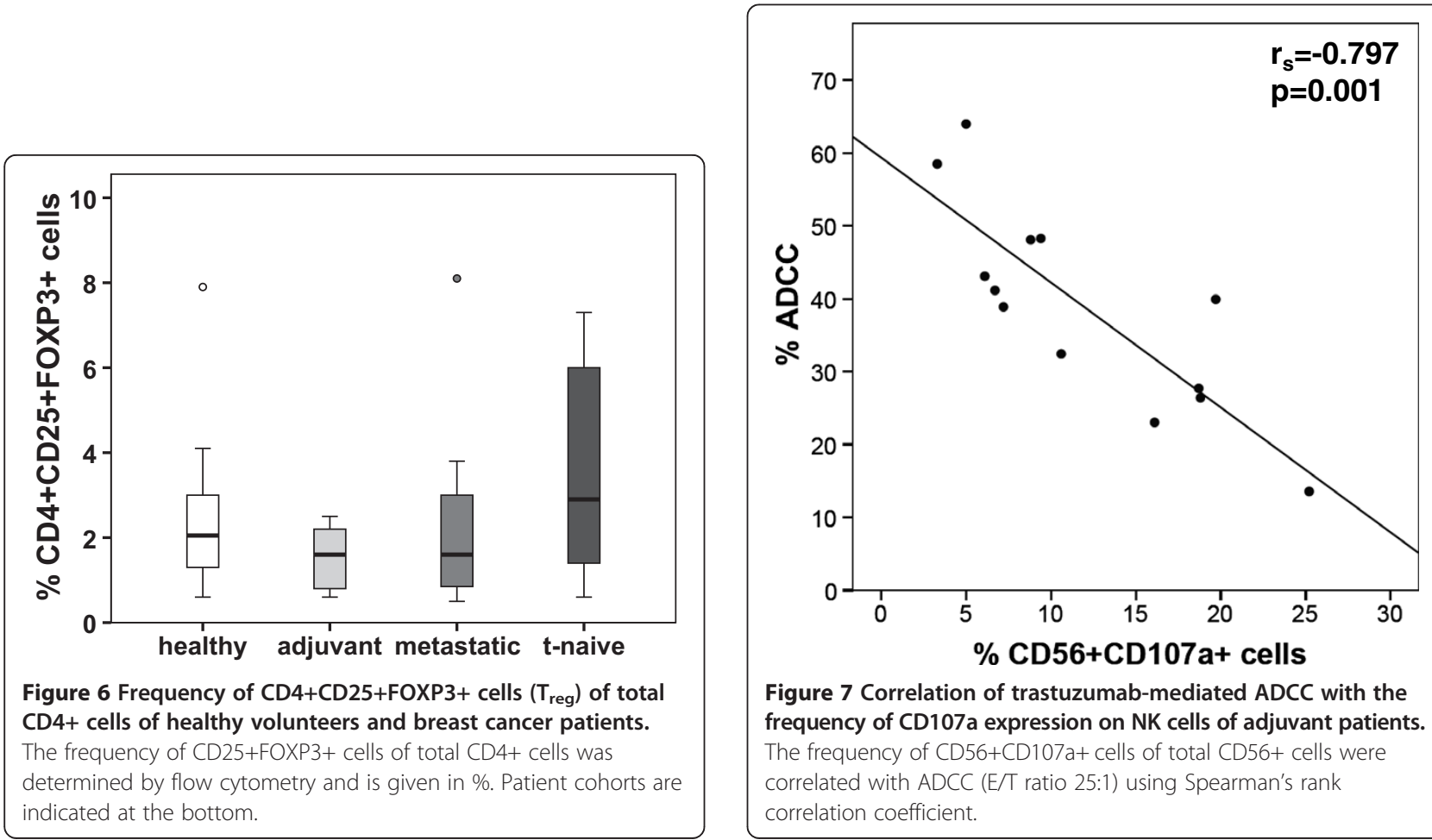

Figure 7 Correlation of trastuzumab-mediated ADCC with the frequency of CD107a expression on NK cells of adjuvant patients. The frequency of CD56+CD107a+ cells of total CD56+ cells were correlated with ADCC (E/T ratio 25:1) using Spearman's rank correlation coefficient. 

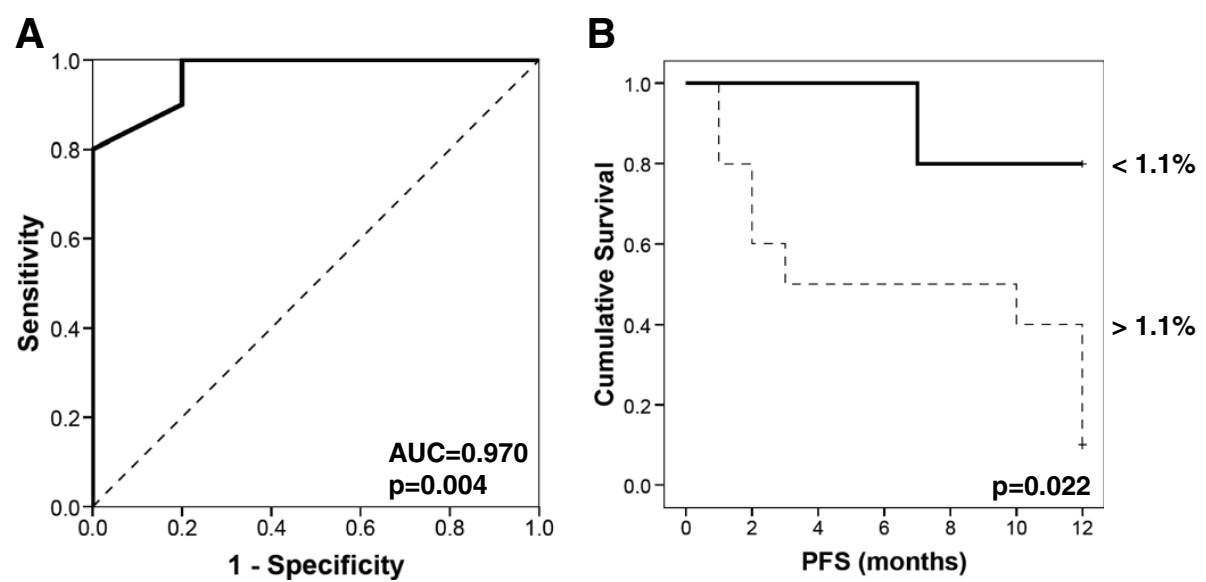

Figure 8 Correlation between the frequency of $\mathrm{T}_{\text {reg }}$ cells and PFS in metastatic breast cancer patients. (A) ROC chart. The area under the curve served for the analysis of potentially diagnostic $T_{\text {reg }}$ cells' sensitivity and specificity to assess the predictive value of $T_{\text {reg }}$ cells on PFS. (B) Kaplan Meier curves evaluating this possible $T_{\text {reg }}$ cut-off value within 12 months of follow-up.

ADCC still occurring in the patient 3 weeks after antibody administration.

Although we found less CD56+ cells expressing CD16 in treated patients, we found a higher frequency of CD16 on CD14+ cells in patients as compared to healthy controls. This showed that ADCP is not associated with a down regulation of cells expressing CD16. An increase of CD14+CD16+ cells might rather be a sign of activation, as this cell type is reported to be increased in patients with acute and chronic infections undergoing hemodialysis [42]. Alternatively, an up regulation of this cell type might be a sign of the malignant disease itself, as intermediate monocytes including CD14+CD16+ cells had been enhanced in tumor patients [43]. This is in line with a study by Feng et al. who even associated an increase of CD14+CD16+ cells with tumor size and pathological staging [44]. Taking the up regulation of CD16 and its affinity to trastuzumab Fc into consideration remains speculative because we did not look at soluble HER2/neu in our patients' sera. It could be that trastuzumab forms complexes with this soluble receptor and binds more efficiently to patients' monocytes that have up regulated CD16. But as our assay was done with isolated PBMCs, tumor cells and artificial addition of trastuzumab, no patient serum is included. Therefore we could not address this phenomenon in our experimental approach.

Furthermore, we analyzed the CD64 expression on CD14+ and CD56+ cells, as this receptor has been documented as a direct potent trigger molecule for ADCC and phagocytosis [45,46]. CD64 was constitutively expressed on monocytes and not altered within any of the groups. On CD56+ cells, CD64 expression was almost undetectable as they usually do not express this receptor.

Additionally, we investigated CD32 expression, a receptor which is involved in phagocytosis. Recently, expression of CD32 in metastatic melanoma has been correlated with an impairment of tumor susceptibility to IgG-dependent cellular response [47]. We did not detect any CD32 expression on our SKBR3 cell line (data not shown), confirming the lack of this receptor in other cancers [48]. Usually monocytes consistently express activating CD32, while inhibitory CD32 is only poorly expressed [49,50], which rather speaks for its role as an activating receptor on those cells. In our study we found a high expression of CD32 on monocytes. However, reduced expression levels did not necessarily correlate with reduced phagocytic activity as monocytes of the t-naive group had an almost normal CD32 expression level but reduced phagocytic activity. We did not find CD32 expression on NK cells, which supports the notion that CD32 is primarily expressed on monocytes and is enriched during phagocytosis [51]. Recently, a novel polymorphism affecting the locus encoding human Fc receptors has been reported that leads to inhibitory CD32 expression on NK cells and has been shown to negatively regulate IgG-induced NK cell activation [52]. Obviously, this mechanism does not apply for our patients.

The initial goal of this study was to determine an immune marker that correlates with ADCC or ADCP activity. Our findings showed negative correlations between CD56+CD107a+ cells and ADCC in the adjuvant setting, which could possibly be a sign of immune activation. Thus, effective therapy might be restrained by chronic stimulation of effector cells.

We are aware of the fact that the healthy volunteers enrolled in our study were younger compared to the investigated breast cancer patients. However, we did not find any correlation between age and ADCC/ADCP activity in patients or healthy volunteers. This is in line with studies on CD56+ and CD14+ cells, reporting that 
the number of both immune populations is preserved or increases with age $[53,54]$ and, although the per-cell activity for cytotoxicity decreases or stays the same, the amount of ADCC is maintained [53]. Therefore, we hypothesize that age-dependent immune-hyporeactivity does not have an impact on our findings.

It is important to note that in this study we used an excess of antibodies in our ex vivo ADCC and ADCP assay as had also been done by Varchetta et al. [26]. This gave us the opportunity to focus on the cellular reactivity of the patients' immune system.

Interestingly, peripheral $\mathrm{T}_{\text {reg }}$ cells, which had been demonstrated to be up regulated during disease progression [55], were not observed to be significantly higher in metastatic patients compared to healthy volunteers, adjuvant or t-naive patients in our study. Moreover, no correlation between the number of $\mathrm{T}_{\text {reg }}$ cells and ADCC or ADCP activity could be observed. One reason might be the fact that trastuzumab itself can lead to a reduction of $\mathrm{T}_{\text {reg }}$ cells [56]. Whether or not this is an effect of chronic immune stimulation by trastuzumab therapy as discussed above remains to be elucidated. Despite a possible down regulation of $\mathrm{T}_{\text {reg }}$ cells by trastuzumab, they were negatively correlated with disease progression in metastatic cancer patients. This effect could be even more prominent in tumor tissue. This indicates that $\mathrm{T}_{\text {reg }}$ cells are of biological relevance within the metastatic patient cohort [57-60]. It should be noted that the number of $\mathrm{T}_{\text {reg }}$ cells in peripheral blood might not be representative of the number of $\mathrm{T}_{\text {reg }}$ cells infiltrating into the tumor or its surrounding tissue.

We are further aware that ADCC also correlates with FcyR-polymorphisms on CD56+CD16+ lymphocytes [26,61-63], but we did not address this point in the present study. To which extent these polymorphisms affect total immune-cell killing mediated by trastuzumab remains unclear and should be further investigated.

\section{Conclusion}

We conclude from our study that trastuzumab-mediated ADCC is reduced in breast cancer patients compared to healthy volunteers but is not further down regulated by disease progression, chemotherapy or prolonged antibody application. Furthermore, results of our work propose $\mathrm{T}_{\text {reg }}$ cells as a potential prognostic factor in metastatic breast cancer.

\section{Additional files}

Additional file 1: Figure S1. Trastuzumab-mediated ADCC of healthy volunteers and breast cancer patients. The extent of ADCC was determined by flow cytometry and is shown in \% of total tumor cell counts. An E/T ratio of 12.5:1 was used. White boxplots represent healthy volunteers, light grey adjuvant, grey metastatic and dark grey trastuzumab naive (t-naive) breast cancer patients. The addition of trastuzumab is indicated at the bottom $(-/+)$.
Additional file 2: Figure S2. Influence of treatment duration and chemotherapy applied in the last 3 months on trastuzumab-mediated ADCC. The extent of ADCC was determined by flow cytometry and is shown in \% of total tumor cell counts. An E/T ratio of 12.5:1 was used. White boxplots represent baseline ADCC without trastuzumab (-) and light grey stimulation with trastuzumab $(+)$. Applied chemotherapy $(C T x)$ is indicated on the bottom.

Additional file 3: Figure $\mathbf{3 3}$. Trastuzumab-mediated ADCC/ADCP of purified NK cells and monocytes of healthy volunteers. The extent of ADCC/ADCP was determined by flow cytometry and is shown in \% of total tumor cell counts. An E/T ratio of 25:1 was used. White boxplots represent baseline ADCC/ADCP without trastuzumab (-) and light grey stimulation with trastuzumab (+). Different cell populations are indicated at the bottom. A) ADCC. B) ADCP.

Additional file 4: Figure S4. Trastuzumab-mediated CDC of healthy volunteers. The extent of CDC was determined by flow cytometry and is shown in \% of total tumor cell counts. An amount of $25 \%$ human serum was used. The addition of trastuzumab is indicated at the bottom $(-/+)$.

Additional file 5: Supplementary methods.

Additional file 6: Figure S6. Correlation of trastuzumab-mediated ADCC with the frequency of CD107a expression on NK cells of adjuvant patients. The frequency of CD56+CD107a+ cells of total CD56+ cells were correlated with ADCC (E/T ratio 12.5:1) using Spearman's rank correlation coefficient.

\section{Abbreviations}

ADCC: Antibody-dependent cell-mediated cytotoxicity; ADCP: Antibodydependent cell-mediated phagocytosis; PMBCs: Peripheral blood mononuclear cells; $T_{\text {reg: }}$ Regulatory $T$ cells; FOXP3: Forkhead-box-protein 3; NK: Natural killer; Th2: Type 2 helper T cells; FcyR: Fc-gamma receptor; LAMP1: Lysosomal-associated membrane protein 1; TNF-a: Tumor necrosis factor alpha; IL: Interleukin; HER2/neu: Human epidermal growth factor receptor 2; mAb: Monoclonal antibody; TAA: Tumor-associated antigens; CTx: Chemotherapy; E: Effector; T: Target; RT: Room temperature; CFSE: Carboxyfluorescein diacetate succinimidyl ester; 7-AAD: 7aminoactinomycin D; FITC: Fluorescein isothiocyanate; PE: Phycoerythrin; APC: Allophycocyanin; ECD: Phycoerythrin-Texas Red conjugate (energy coupled dye); PC5: Phycoerythrin-cyanine 5 conjugate; FCS: Fetal calf serum; DMSO: Dimethyl sulfoxide; EDTA: Ethylene diamine tetra-acetic acid; IQR: Interquartile range; AUC: Area under the curve; ROC: Receiver operating characteristic; PFS: Progression-free survival; RECIST: Response evaluation criteria in solid tumors.

\section{Competing interests}

The authors declare that they have no competing interests.

\section{Authors' contributions}

BP designed, performed the experiment and wrote the manuscript. JL performed the experiment, carried out the statistical analysis and wrote the manuscript. JS, EJJ, JF and MS designed the experiment. GS and RB enrolled the patients and critically analyzed the data. MB designed the experiment and wrote the manuscript. All authors read and approved the final manuscript.

\section{Acknowledgements}

We thank Rudolf Oehler and other members of the surgical research laboratory of the Medical University of Vienna for critical and helpful discussions. Moreover, we would like to express our special thanks to Herbert Kaiser for his precise proofreading. JS, JF and EJJ were supported by grants W1205-B09 (PhD program (CHD) and P23398-B11 of the Austrian Science Fund FWF.

\section{Author details}

${ }^{1}$ Department of Surgery, Medical University of Vienna, Vienna General Hospital, Waehringer Guertel 18-20, Vienna A-1090, Austria. ${ }^{2}$ Comparative Medicine, Messerli Research Institute of the University of Veterinary Medicine Vienna, Medical University of Vienna and University of Vienna, Veterinaerplatz 1, Vienna A-1210, Austria. ${ }^{3}$ Comparative Immunology and Oncology, Department of Pathophysiology and Allergy Research, Center of Pathophysiology, Infectiology and Immunology, Medical University of Vienna, 
Vienna General Hospital, Waehringer Guertel 18-20, Vienna A-1090, Austria. ${ }^{4}$ Department of Oncology, Medical University of Vienna, Vienna General Hospital, Waehringer Guertel 18-20, Vienna A-1090, Austria. ${ }^{5}$ Comprehensive Cancer Center Vienna, Spitalgasse 23, Vienna A-1090, Austria.

Received: 28 April 2013 Accepted: 9 December 2013

Published: 12 December 2013

\section{References}

1. Joensuu H, Bono P, Kataja V, Alanko T, Kokko R, Asola R, Utriainen T, Turpeenniemi-Hujanen T, Jyrkkio S, Moykkynen K, et al: Fluorouracil, epirubicin, and cyclophosphamide with either docetaxel or vinorelbine, with or without trastuzumab, as adjuvant treatments of breast cancer: final results of the FinHer Trial. J Clin Oncol 2009, 27:5685-5692.

2. Joensuu H, Kellokumpu-Lehtinen PL, Bono P, Alanko T, Kataja V, Asola R, Utriainen T, Kokko R, Hemminki A, Tarkkanen M, et al: Adjuvant docetaxel or vinorelbine with or without trastuzumab for breast cancer. $N$ Engl J Med 2006, 354:809-820.

3. Perez EA, Romond EH, Suman VJ, Jeong JH, Davidson NE, Geyer CE Jr, Martino S, Mamounas EP, Kaufman PA, Wolmark N: Four-year follow-up of trastuzumab plus adjuvant chemotherapy for operable human epidermal growth factor receptor 2-positive breast cancer: joint analysis of data from NCCTG N9831 and NSABP B-31. J Clin Oncol 2011, 29:3366-3373.

4. Piccart-Gebhart MJ, Procter M, Leyland-Jones B, Goldhirsch A, Untch M, Smith I, Gianni L, Baselga J, Bell R, Jackisch C, et al: Trastuzumab after adjuvant chemotherapy in HER2-positive breast cancer. $N$ Engl J Med 2005, 353:1659-1672

5. Smith I, Procter M, Gelber RD, Guillaume S, Feyereislova A, Dowsett M, Goldhirsch A, Untch M, Mariani G, Baselga J, et al: 2-year follow-up of trastuzumab after adjuvant chemotherapy in HER2-positive breast cancer: a randomised controlled trial. Lancet 2007, 369:29-36.

6. Yin W, Jiang Y, Shen $Z$, Shao Z, Lu J: Trastuzumab in the adjuvant treatment of HER2-positive early breast cancer patients: a meta-analysis of published randomized controlled trials. PLOS One 2011, 6:e21030.

7. Aebi S, Davidson T, Gruber G, Cardoso F: Primary breast cancer: ESMO clinical practice guidelines for diagnosis, treatment and follow-up. Ann Oncol 2011, 22(Suppl 6):vi12-vi24

8. Cardoso F, Harbeck N, Fallowfield L, Kyriakides S, Senkus E: Locally recurrent or metastatic breast cancer: ESMO clinical practice guidelines for diagnosis, treatment and follow-up. Ann Oncol 2012, 23(Suppl 7):vii11-vii19.

9. Goldhirsch A, Wood WC, Coates AS, Gelber RD, Thurlimann B, Senn HJ: Strategies for subtypes-dealing with the diversity of breast cancer: highlights of the St. Gallen International expert consensus on the primary therapy of early breast cancer 2011. Ann Oncol 2011, 22:1736-1747

10. Cobleigh MA, Vogel CL, Tripathy D, Robert NJ, Scholl S, Fehrenbacher L, Wolter JM, Paton V, Shak S, Lieberman G, Slamon DJ: Multinational study of the efficacy and safety of humanized anti-HER2 monoclonal antibody in women who have HER2-overexpressing metastatic breast cancer that has progressed after chemotherapy for metastatic disease. J Clin Oncol 1999, 17:2639-2648.

11. Pegram MD, Lipton A, Hayes DF, Weber BL, Baselga JM, Tripathy D, Baly D, Baughman SA, Twaddell T, Glaspy JA, Slamon DJ: Phase II study of receptor-enhanced chemosensitivity using recombinant humanized anti-p185HER2/neu monoclonal antibody plus cisplatin in patients with HER2/neu-overexpressing metastatic breast cancer refractory to chemotherapy treatment. J Clin Oncol 1998, 16:2659-2671.

12. Baselga J, Tripathy D, Mendelsohn J, Baughman S, Benz CC, Dantis L, Sklarin NT, Seidman AD, Hudis CA, Moore J, et al: Phase II study of weekly intravenous recombinant humanized anti-p185HER2 monoclonal antibody in patients with HER2/neu-overexpressing metastatic breast cancer. J Clin Oncol 1996, 14:737-744.

13. Hudis CA: Trastuzumab-mechanism of action and use in clinical practice. N Engl J Med 2007, 357:39-51.

14. Mohsin SK, Weiss HL, Gutierrez MC, Chamness GC, Schiff R, Digiovanna MP, Wang CX, Hilsenbeck SG, Osborne CK, Allred DC, et al: Neoadjuvant trastuzumab induces apoptosis in primary breast cancers. J Clin Oncol 2005, 23:2460-2468
15. Molina MA, Codony-Servat J, Albanell J, Rojo F, Arribas J, Baselga J: Trastuzumab (herceptin), a humanized anti-Her2 receptor monoclonal antibody, inhibits basal and activated Her2 ectodomain cleavage in breast cancer cells. Cancer Res 2001, 61:4744-4749.

16. Spector NL, Blackwell KL: Understanding the mechanisms behind trastuzumab therapy for human epidermal growth factor receptor 2-positive breast cancer. J Clin Oncol 2009, 27:5838-5847.

17. Valabrega G, Montemurro F, Aglietta M: Trastuzumab: mechanism of action, resistance and future perspectives in HER2-overexpressing breast cancer. Ann Oncol 2007, 18:977-984.

18. Tanner M, Kapanen Al, Junttila T, Raheem O, Grenman S, Elo J, Elenius K, Isola J: Characterization of a novel cell line established from a patient with Herceptin-resistant breast cancer. Mol Cancer Ther 2004, 3:1585-1592.

19. Burstein HJ, Harris LN, Gelman R, Lester SC, Nunes RA, Kaelin CM, Parker LM, Ellisen LW, Kuter I, Gadd MA, et al: Preoperative therapy with trastuzumab and paclitaxel followed by sequential adjuvant doxorubicin/ cyclophosphamide for HER2 overexpressing stage II or III breast cancer: a pilot study. J Clin Oncol 2003, 21:46-53.

20. Kute TE, Savage L, Stehle JR Jr, Kim-Shapiro JW, Blanks MJ, Wood J, Vaughn JP: Breast tumor cells isolated from in vitro resistance to trastuzumab remain sensitive to trastuzumab anti-tumor effects in vivo and to ADCC killing. Cancer Immunol Immunother 2009, 58:1887-1896.

21. Kute $T$, Lack CM, Willingham M, Bishwokama B, Williams $H$, Barrett $K$, Mitchell T, Vaughn JP: Development of herceptin resistance in breast cancer cells. Cytometry A 2004, 57:86-93.

22. Clynes RA, Towers TL, Presta LG, Ravetch JV: Inhibitory Fc receptors modulate in vivo cytotoxicity against tumor targets. Nat Med 2000, 6:443-446.

23. Spiridon $\mathrm{Cl}$, Guinn S, Vitetta ES: A comparison of the in vitro and in vivo activities of $\lg G$ and $F\left(a b^{\prime}\right) 2$ fragments of a mixture of three monoclonal anti-Her-2 antibodies. Clin Cancer Res 2004, 10:3542-3551.

24. Lowe DB, Shearer MH, Jumper CA, Bright RK, Kennedy RC: Fc gamma receptors play a dominant role in protective tumor immunity against a virus-encoded tumor-specific antigen in a murine model of experimental pulmonary metastases. J Virol 2007, 81:1313-1318.

25. Gennari R, Menard S, Fagnoni F, Ponchio L, Scelsi M, Tagliabue E, Castiglioni F, Villani L, Magalotti C, Gibelli N, et al: Pilot study of the mechanism of action of preoperative trastuzumab in patients with primary operable breast tumors overexpressing HER2. Clin Cancer Res 2004, 10:5650-5655.

26. Varchetta S, Gibelli N, Oliviero B, Nardini E, Gennari R, Gatti G, Silva LS, Villani $L$, Tagliabue E, Menard S, et al: Elements related to heterogeneity of antibody-dependent cell cytotoxicity in patients under trastuzumab therapy for primary operable breast cancer overexpressing Her2. Cancer Res 2007, 67:11991-11999.

27. Beano A, Signorino E, Evangelista A, Brusa D, Mistrangelo M, Polimeni MA, Spadi R, Donadio M, Ciuffreda L, Matera L: Correlation between NK function and response to trastuzumab in metastatic breast cancer patients. J Trans/ Med 2008, 6:25.

28. Parihar R, Nadella P, Lewis A, Jensen R, De Hoff C, Dierksheide JE, VanBuskirk AM, Magro CM, Young DC, Shapiro CL, Carson WE III: A phase I study of interleukin 12 with trastuzumab in patients with human epidermal growth factor receptor-2-overexpressing malignancies: analysis of sustained interferon gamma production in a subset of patients. Clin Cancer Res 2004 10:5027-5037.

29. Repka T, Chiorean EG, Gay J, Herwig KE, KohI VK, Yee D, Miller JS: Trastuzumab and interleukin-2 in HER2-positive metastatic breast cancer a pilot study. Clin Cancer Res 2003, 9:2440-2446.

30. Tagliabue E, Campiglio M, Pupa SM, Menard S, Balsari A: Activity and resistance of trastuzumab according to different clinical settings. Cancer Treat Rev 2012, 38:212-217.

31. Bracher M, Gould HJ, Sutton BJ, Dombrowicz D, Karagiannis SN: Three-colour flow cytometric method to measure antibody-dependent tumour cell killing by cytotoxicity and phagocytosis. J Immunol Methods 2007, 323:160-171.

32. Karagiannis P, Singer J, Hunt J, Gan SK, Rudman SM, Mechtcheriakova D, Knittelfelder R, Daniels TR, Hobson PS, Beavil AJ, et al: Characterisation of an engineered trastuzumab $\lg \mathrm{E}$ antibody and effector cell mechanisms targeting HER2/neu-positive tumour cells. Cancer Immunol Immunother 2009, 58:915-930.

33. Mamidi S, Cinci M, Hasmann M, Fehring V, Kirschfink M: Lipoplex mediated silencing of membrane regulators (CD46, CD55 and CD59) enhances complement-dependent anti-tumor activity of trastuzumab and pertuzumab. Mol Oncol 2013, 7:580-594. 
34. Aktas E, Kucuksezer UC, Bilgic S, Erten G, Deniz G: Relationship between CD107a expression and cytotoxic activity. Cell Immunol 2009, 254:149-154

35. Alter G, Malenfant JM, Altfeld M: CD107a as a functional marker for the identification of natural killer cell activity. J Immunol Methods 2004 , 294:15-22.

36. Pivot X, Romieu G, Debled M, Pierga JY, Kerbrat P, Bachelot T, Lortholary A, Espie M, Fumoleau P, Serin D, et al: 6 months versus 12 months of adjuvant trastuzumab for patients with HER2-positive early breast cancer (PHARE): a randomised phase 3 trial. Lancet Oncol 2013, 14:741-748.

37. Cancello G, Montagna E, D’Agostino D, Giuliano M, Giordano A, Di Lorenzo G, Plaitano M, De Placido S, De Laurentiis M: Continuing trastuzumab beyond disease progression: outcomes analysis in patients with metastatic breast cancer. Breast Cancer Res 2008, 10:R60

38. Von Minckwitz G, Du Bois A, Schmidt M, Maass N, Cufer T, De Jongh FE, Maartense E, Zielinski C, Kaufmann M, Bauer W, et al: Trastuzumab beyond progression in human epidermal growth factor receptor 2-positive advanced breast cancer: a german breast group 26/breast international group 03-05 study. J Clin Oncol 2009, 27:1999-2006.

39. Yerushalmi R, Gelmon K: Treatment beyond progression: is it moving from belief to evidence? Oncologist 2010, 15:796-798.

40. Mozaffari F, Lindemalm C, Choudhury A, Granstam-Bjorneklett H, Helander I, Lekander M, Mikaelsson E, Nilsson B, Ojutkangas ML, Osterborg A, et al: NK-cell and T-cell functions in patients with breast cancer: effects of surgery and adjuvant chemo-and radiotherapy. Br J Cancer 2007, 97:105-111.

41. Tsavaris N, Kosmas C, Vadiaka M, Kanelopoulos P, Boulamatsis D: Immune changes in patients with advanced breast cancer undergoing chemotherapy with taxanes. Br J Cancer 2002, 87:21-27.

42. Nockher WA, Scherberich JE: Expanded CD14+ CD16+ monocyte subpopulation in patients with acute and chronic infections undergoing hemodialysis. Infect Immun 1998, 66:2782-2790.

43. Schauer $D$, Starlinger $P$, Reiter $C$, Jahn N, Zajc $P$, Buchberger $E$, BachleitnerHofmann T, Bergmann M, Stift A, Gruenberger T, Brostjan C: Intermediate monocytes but not TIE2-expressing monocytes are a sensitive diagnostic indicator for colorectal cancer. PLoS One 2012, 7:e44450.

44. Feng AL, Zhu JK, Sun JT, Yang MX, Neckenig MR, Wang XW, Shao QQ, Song $\mathrm{BF}$, Yang QF, Kong BH, Qu X: CD16+ monocytes in breast cancer patients: expanded by monocyte chemoattractant protein- 1 and may be useful for early diagnosis. Clin Exp Immunol 2011, 164:57-65.

45. Watanabe M, Wallace PK, Keler T, Deo YM, Akewanlop C, Hayes DF: Antibody dependent cellular phagocytosis (ADCP) and antibody dependent cellular cytotoxicity (ADCC) of breast cancer cells mediated by bispecific antibody, MDX-210. Breast Cancer Res Treat 1999, 53:199-207.

46. Van Ojik HH, Bevaart L, Dahle CE, Bakker A, Jansen MJ, Van Vugt MJ, van de Winkel JG, Weiner GJ: CpG-A and B oligodeoxynucleotides enhance the efficacy of antibody therapy by activating different effector cell populations. Cancer Res 2003, 63:5595-5600.

47. Cassard L, Cohen-Solal JF, Galinha A, Sastre-Garau X, Mathiot C, Galon J, Dorval T, Bernheim A, Fridman WH, Sautes-Fridman C: Modulation of tumor growth by inhibitory $\mathrm{Fc}$ (gamma) receptor expressed by human melanoma cells. J Clin Invest 2002, 110:1549-1557.

48. Cassard L, Cohen-Solal JF, Fournier EM, Camilleri-Broet S, Spatz A, Chouaib S, Badoual C, Varin A, Fisson S, Duvillard P, et al: Selective expression of inhibitory Fcgamma receptor by metastatic melanoma impairs tumor susceptibility to IgG-dependent cellular response. Int J Cancer 2008, 123:2832-2839.

49. Magnusson SE, Engstrom M, Jacob U, Ulfgren AK, Kleinau S: High synovial expression of the inhibitory FcgammaRllb in rheumatoid arthritis. Arthritis Res Ther 2007, 9:R51.

50. Su K, Yang H, Li X, Gibson AW, Cafardi JM, Zhou T, Edberg JC, Kimberly RP: Expression profile of FcgammaRllb on leukocytes and its dysregulation in systemic lupus erythematosus. J Immunol 2007, 178:3272-3280.

51. Syam S, Mero P, Pham T, Mclntosh CA, Bruhns P, Booth JW: Differential recruitment of activating and inhibitory Fc gamma RII during phagocytosis. J Immunol 2010, 184:2966-2973.

52. van der Heijden J, Breunis WB, Geissler J, De Boer M, van den Berg TK Kuijpers TW: Phenotypic variation in IgG receptors by nonclassical FCGR2C alleles. J Immuno/ 2012, 188:1318-1324.

53. Gayoso I, Sanchez-Correa B, Campos C, Alonso C, Pera A, Casado JG, Morgado S, Tarazona R, Solana R: Immunosenescence of human natural killer cells. J Innate Immun 2011, 3:337-343.
54. Seidler S, Zimmermann HW, Bartneck M, Trautwein C, Tacke F: Age-dependent alterations of monocyte subsets and monocyte-related chemokine pathways in healthy adults. BMC Immuno/ 2010, 11:30

55. Liyanage UK, Moore TT, Joo HG, Tanaka Y, Herrmann V, Doherty G, Drebin JA, Strasberg SM, Eberlein TJ, Goedegebuure PS, Linehan DC: Prevalence of regulatory $T$ cells is increased in peripheral blood and tumor microenvironment of patients with pancreas or breast adenocarcinoma. J Immunol 2002, 169:2756-2761.

56. Horlock C, Stott B, Dyson PJ, Morishita M, Coombes RC, Savage P, Stebbing $\mathrm{J}$ : The effects of trastuzumab on the CD4 + CD25 + FoxP3+ and CD4 + IL17A + T-cell axis in patients with breast cancer. Br J Cancer 2009, 100:1061-1067.

57. Bates GJ, Fox SB, Han C, Leek RD, Garcia JF, Harris AL, Banham AH: Quantification of regulatory $T$ cells enables the identification of high-risk breast cancer patients and those at risk of late relapse. J Clin Oncol 2006, 24:5373-5380

58. Bohling SD, Allison $\mathrm{KH}$ : Immunosuppressive regulatory $\mathrm{T}$ cells are associated with aggressive breast cancer phenotypes: a potential therapeutic target. Mod Pathol 2008, 21:1527-1532.

59. Gobert M, Treilleux I, Bendriss-Vermare N, Bachelot T, Goddard-Leon S, Arfi $\checkmark$, Biota C, Doffin AC, Durand I, Olive D, et al: Regulatory T cells recruited through CCL22/CCR4 are selectively activated in lymphoid infiltrates surrounding primary breast tumors and lead to an adverse clinical outcome. Cancer Res 2009, 69:2000-2009.

60. Ladoire S, Arnould L, Apetoh L, Coudert B, Martin F, Chauffert B, Fumoleau $P$, Ghiringhelli F: Pathologic complete response to neoadjuvant chemotherapy of breast carcinoma is associated with the disappearance of tumor-infiltrating foxp3+ regulatory T cells. Clin Cancer Res 2008, 14:2413-2420

61. Musolino A, Naldi N, Bortesi B, Pezzuolo D, Capelletti M, Missale G, Laccabue D, Zerbini A, Camisa R, Bisagni G, et al: Immunoglobulin $G$ fragment $C$ receptor polymorphisms and clinical efficacy of trastuzumab-based therapy in patients with HER-2/neu-positive metastatic breast cancer. J Clin Oncol 2008, 26:1789-1796.

62. Tamura K, Shimizu C, Hojo T, Akashi-Tanaka S, Kinoshita T, Yonemori K, Kouno T, Katsumata N, Ando M, Aogi K, et al: FcgammaR2A and 3A polymorphisms predict clinical outcome of trastuzumab in both neoadjuvant and metastatic settings in patients with HER2-positive breast cancer. Ann Oncol 2011, 22:1302-1307.

63. Ferris RL, Jaffee EM, Ferrone S: Tumor antigen-targeted, monoclonal antibody-based immunotherapy: clinical response, cellular immunity, and immunoescape. J Clin Oncol 2010, 28:4390-4399.

doi:10.1186/1479-5876-11-307

Cite this article as: Petricevic et al:: Trastuzumab mediates antibody-dependent cell-mediated cytotoxicity and phagocytosis to the same extent in both adjuvant and metastatic HER2/neu breast cancer patients. Journal of Translational Medicine 2013 11:307.

\section{Submit your next manuscript to BioMed Central and take full advantage of:}

- Convenient online submission

- Thorough peer review

- No space constraints or color figure charges

- Immediate publication on acceptance

- Inclusion in PubMed, CAS, Scopus and Google Scholar

- Research which is freely available for redistribution 